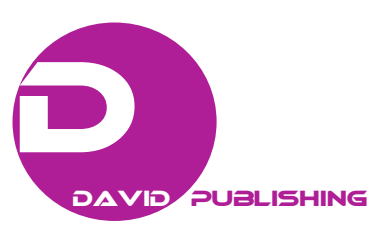

\title{
A Study of Renal Transplant for Patients with Neurogenic Bladder
}

\author{
Yoshiko Matsuda $^{1,2}$, Takahisa Hiramitsu², Koji Nanmoku², Takayuki Yamamoto², Makoto Tsujita ${ }^{2}$, Norihiko \\ Goto $^{2}$ and Yoshihiko Watarai ${ }^{2}$ \\ 1. Department of Transplant Immunology, University of Nagoya, Nagoyashi 466-8650, Japan \\ 2. Department of Transplant and Endocrine Surgery, Nagoya Second Red Cross Hospital, Nagoyashi 466-8650, Japan
}

\begin{abstract}
In our hospital, we performed renal transplants on 12 patients with neurogenic bladder between 1992 and 2010 . Three patients with bladder dysfunction had undergone pre-operative cystoplasties for the improvement of their bladder compliance. Patients were divided into high-risk and low-risk groups according to risk of urinary tract complications and infections after renal transplants. The levels of risk were determined on the basis the patients' pre-operative bladder functions and urination states, and the two groups were compared with respect to the incidence of post-operative UTIs (urinary tract infections) and level of renal function. All patients, except a female who could not perform regular CIC (clean intermittent catheterizations) to maintain adequate urine output, were able to maintain renal function. A recipient was able to deliver a baby safely. In addition, we were able to treat post-operative UTIs by increasing the frequency of CICs and by adding a night balloon.
\end{abstract}

Key words: Renal transplantation, neurogenic bladder, clean intermittent catheterization, cystoplasty.

\section{Introduction}

Neurogenic bladder, which is a very serious urological disease, is associated to CRF (chronic renal failure) [1]. Renal transplants in patients with neurogenic bladder involve high risk because of the impact of the neurogenic bladder on renal graft function, urinary tract complications and infection control [2]. Neurogenic bladder was previously considered a relative contraindication of renal transplants. However, renal transplantation has recently become feasible in this condition because of advancements in the diagnostic, treatment and management methods of lower urinary tract disorders [3-5]. In this study, we placed all of the patients with neurogenic bladder into a high-risk group because of their potential for urinary tract complications and compared the post-operative management in this group

Corresponding author: Yoshiko Matsuda, M.D., research fields: kidney transplantation, B cell biology, transplant immunology, auto immune system and anti-body mediated rejection. E-mail: star3david@yahoo.co.jp. with that in others. The aim of this study was to evaluate criteria for choosing between conservative or surgical treatments in patients with neurogenic bladder on the basis of pre-operative bladder evaluation.

\section{Patients and Methods}

Of the patients undergoing renal transplantation at this facility between 1992 and 2010, the pre-operative and post-operative management of 12 patients with urogenic bladder were studied with regard to post-operative complications and the mid/long-term prognoses of the renal grafts. Six male and six female patients aged between 4 and 61 years at the time of the transplantation were selected. This clinical research was conducted in accordance with the guidelines of Helsinki Declaration (1975) and the study protocols were approved by the Ethics Committee of Human Experimentation in Japan.

\section{Statistical Techniques}

Statistical analysis was performed with SPSS 
software, version 19 (SPSS, Chicago, IL, USA). Significance of differences between high-risk and low-risk group regarding post-operative complication or management was tested by means of paired $t$ test. Test was considered to be significant at $P<0.05$. The authors have adhered to the STROBE statement guidelines for reporting observational studies.

\section{Results}

CIC (clean intermittent self-catheterization) was performed in all 12 patients during the post-operative urinary management for a follow-up period of (mean \pm SD (standard deviation)) $67.9 \pm 54.0$ months (range, 19-29 months). Six patients were male and six were female. The mean \pm SD age at the time of the renal transplantation was $36.5 \pm 18.6$ years (range, 4-61 years). Table 1 lists the aetiologies of CRF, detailed patient characteristics and pre-operative bladder function (Table 2) in all 12 patients. The aetiology was idiopathic in four patients, pelvic surgery in two patients, spina bifida in three patients, spinal surgery in two patients and diabetic neuropathy in one patient. The indirect causes of CRF were diabetic nephropathy, chronic glomerulonephritis and resection of both kidneys, whereas those directly related to neurogenic bladder were VUR (vesicoureteral reflux), hydronephrosis and complex UTIs (urinary tract infections). Ten living donor kidneys and two cadaveric kidneys were used for the transplantations. Cystoplasties were performed before or after the transplants in three patients in whom increased intra-vesical pressure detected pre-operatively.

Post-operative febrile UTIs were observed in 10 of the 12 patients. Renal transplantation was successful in all patients but one, in whom failure was because of noncompliance. Furthermore, the patients were divided into a high-risk group consisting of seven patients with residual urine and hydronephrosis, and a low-risk group consisting of the other five patients (Tables 3 and 4). The incidence of post-operative UTIs was 1.00 \pm 0.76 times/month in the high-risk group and $0.27 \pm$ 0.34 times/month in the low-risk group. Moreover, there were no significant differences between the two groups regarding the frequency of UTIs and for renal function ( $P=0.18, P=0.65$, respectively). A night balloon was required in four of the seven high-risk patients and in one of the five low-risk patients. Serum creatinine, a parameter of post-transplant renal function, was $1.05 \pm 0.89 \mathrm{mg} / \mathrm{dL}$ in the high-risk group and $1.35 \pm 0.36 \mathrm{mg} / \mathrm{dL}$ in the low-risk group. There was no significant difference between the two groups regarding the frequency of CIC after surgery (low-risk group, 7.8 times a day; high-risk group, 7.66 times a day; $P=0.89$ ) (Table 5).

In addition, we used a contemporary balloon catheter with clean intermittent catheterization and the normal balloon-based catheter for withdrawal of urine

Table 1 Theaetiologies of CRF, detailed patient characteristics.

\begin{tabular}{|c|c|c|c|c|c|}
\hline Gender & $\begin{array}{l}\text { Age at transplantation } \\
\text { (year) }\end{array}$ & $\begin{array}{l}\text { Post-operative follow } \\
\text { up period (months) }\end{array}$ & Donor type & The aetiologies of CRF & $\begin{array}{l}\text { The cause of chronic renal } \\
\text { failure }\end{array}$ \\
\hline Male & 54 & 76 & Living & Idiopathic & Reflux nephropathy \\
\hline Female & 39 & 37 & Decreased & Pelvic surgery & Urinary tract infection \\
\hline Female & 32 & 43 & Living & Pelvic surgery & Pyelonephritis \\
\hline Female & 53 & 42 & Living & Spina bifida & Urinary tract infection \\
\hline Male & 16 & 58 & Living & Idiopathic & Hydronephrosis \\
\hline Female & 24 & 119 & Living & Spina bifida & Hydronephrosis \\
\hline Female & 17 & 130 & Living & Spinal surgery & Reflux nephropathy \\
\hline Male & 4 & 229 & Living & Idiopathic & Reflux nephropathy \\
\hline Female & 61 & 19 & Living & Idiopathic & Bilateral nephrectomy \\
\hline Male & 25 & 35 & Living & Spina bifida & Hydronephrosis \\
\hline Male & 59 & 43 & Living & Diabetic nephropathy & Diabetic nephropathy \\
\hline Male & 54 & 226 & Decreased & Spinal surgery & Chronic glomerulonephritis \\
\hline
\end{tabular}


Table 2 Individual bladder function and urination states preoperatively.

\begin{tabular}{|c|c|c|c|c|c|}
\hline Case No & $\begin{array}{l}\text { Bladder capacity } \\
(\mathrm{mL})\end{array}$ & VUR (grade) & $\begin{array}{l}\text { Intravesical pressure } \\
\left(\mathrm{cm} \mathrm{H} \mathrm{H}_{2} \mathrm{O}\right)\end{array}$ & Residual urine $(\mathrm{mL})$ & Urination states \\
\hline 1 & 700 & 0 & UD & 0 & Dysuria \\
\hline 2 & 80 & 3 & UD & ND & Dysuria, chronic cystitis \\
\hline 3 & 577 & 0 & UD & 200 & Not particular \\
\hline 4 & 320 & 0 & UD & ND & Reccurence of utis \\
\hline 5 & 488 & 0 & 14 & Large quantity & Pyonephrosis \\
\hline 6 & 60 & 5 & Low & ND & Reccurence of utis \\
\hline 7 & 400 & 1 & Low & Low & Abdominal straining, during micturition \\
\hline 8 & UD & 3 & UD & ND & Reccurence of utis \\
\hline 9 & 350 & 3 & 7 & ND & Incontinence \\
\hline 10 & 250 & 5 & 37 & ND & Incontinence \\
\hline 11 & 120 & 0 & UD & 290 & Incontinence \\
\hline 12 & 320 & 0 & UD & 45 & Dysuria \\
\hline
\end{tabular}

UD: undetectable; ND: no data.

Table 3 Low-risk group in five kidney recipients.

\begin{tabular}{lllllll}
\hline $\begin{array}{l}\text { No. } \begin{array}{l}\text { Pre-operative } \\
\text { treatment }\end{array} \\
\text { frequency of CIC (/day) }\end{array}$ & $\begin{array}{l}\text { The post-operative } \\
\text { frelloon }\end{array}$ & $\begin{array}{l}\text { Use of night } \\
\text { frequency of UTIs } \\
\text { (/months) }\end{array}$ & Oral medicine & $\begin{array}{l}\text { Current serum } \\
\text { creatinie } \\
\text { (mg/dL) }\end{array}$ \\
\hline 3 & CIC & 12 & $(-)$ & 0 & None & 1.6 \\
5 & Nephrectomy, CIC & 12 & $(-)$ & 0 & None & 1.36 \\
7 & CIC & 5 & $(+)$ & $4 / 56$ & None & 1.84 \\
12 & CIC & 3 & $(-)$ & $4 / 116$ & None & 1.19 \\
\hline
\end{tabular}

Table 4 High-risk group in seven kidney recipients.

\begin{tabular}{|c|c|c|c|c|c|c|}
\hline No. & Pre-operative treatment & $\begin{array}{l}\text { The post-operative } \\
\text { frequency of CIC } \\
\text { (/day) }\end{array}$ & $\begin{array}{l}\text { Use of night } \\
\text { balloon }\end{array}$ & $\begin{array}{l}\text { The post-operative } \\
\text { frequency of UTIs } \\
\text { (/month) }\end{array}$ & Oral medicine & $\begin{array}{l}\text { Current serum } \\
\text { creatinie }(\mathrm{mg} / \mathrm{dL})\end{array}$ \\
\hline 2 & $\begin{array}{l}\text { CIC, } \\
\text { nephrectomy }\end{array}$ & 12 & $(+)$ & $1 / 37$ & None & 1.08 \\
\hline 4 & $\mathrm{CIC}$ & 4 & $(+)$ & $3 / 16$ & $\alpha$-blocker & 1.22 \\
\hline 10 & $\mathrm{CIC}$ & 16 & $(+)$ & $1 / 34$ & Anticholinergic agent & 1.12 \\
\hline 11 & CIC & 3 & $(-)$ & $1 / 116$ & Anticholinergic agent & 0.78 \\
\hline 6 & $\begin{array}{l}\text { CIC, bladderirrigation, } \\
\text { cystoplasty }\end{array}$ & 7 & $(-)$ & $4 / 117$ & None & 2.13 \\
\hline 8 & $\begin{array}{l}\text { CIC, bladderirrigation, } \\
\text { cystoplasty }\end{array}$ & 4 & $(-)$ & $1 / 117$ & None & $\begin{array}{l}\text { Reintroduction to } \\
\text { dialysis therapy }\end{array}$ \\
\hline 9 & CIC, cystoplasty & 7 & $(+)$ & $5 / 17$ & None & 1.05 \\
\hline
\end{tabular}

Table 5 The differences between the two groups regarding following factors.

\begin{tabular}{llll}
\hline & Low-risk group & $\begin{array}{l}\text { High-risk group [cystoplasties (-)]/High-risk } \\
\text { group [cystoplasties (+)] }\end{array}$ & $P$ value \\
\hline Use of night balloon (n/all cases) & $1 / 4$ & $4 / 7$ & 0.22 \\
Post-operative frequency of UTIs (/month) & $106.6 \pm 74.4$ & $39.25 \pm 3.34 / 122.33 \pm 85.76$ & 0.18 \\
The post-operative frequency of CIC (/day) & $0.27 \pm 0.34$ & $1.00 \pm 0.76 / 1.35 \pm 1.90$ & 0.89 \\
Post-operative follow up period (months) & 7.8 & $8.8 / 6$ & 0.65 \\
Current serum creatinie (mg/dL) & $1.35 \pm 0.36$ & $1.05 \pm 0.189 / 1.59 \pm 0.76^{*}$ & 0.65 \\
\hline
\end{tabular}

*Except for the patient who has re-introduced to dialysis. 
samples during the day and night, respectively. We sterilized the catheters and reused it.

\section{Discussion}

The most important factors in the treatment of patients with neurogenic bladder who undergo renal transplantation are the preservation of the renal graft, management of incontinence and prevention of UTIs. Especially, the immunosuppressive agents administered during transplantation have a particular impact on the patient immunity [6,7]. Therefore, we focused on the management of UTI before and after transplantation. First, we removed or replaced the balloon catheter before initiating the treatment. After the diagnosis of UTI, we performed urinary culture and an antibiotic susceptibility test. Moreover, we performed Gram staining of the urine samples; we administered an antibacterial agent effective against enterococci when the Gram-positive cocci were detected. Alternatively, we administered a broad-spectrum antibacterial agent effective against Pseudomonas aeruginosa.

When the results of the antibiotic susceptibility test were obtained, we administered appropriate antibacterial agents, if required. For example, we administered vancomycin against methicillin-resistant Staphylococcus aureus and carbapenems against extended-spectrum

beta-lactamase-producing pathogens by determining the dose based on glomerular filtration rate.

Next, we evaluated the factors that influence all possible complications of the urinary tract after renal transplantation. Furthermore, we evaluated the post-operative management of these patients and analysed all factors that had an impact on the patient quality of life. In our hospital, we performed 12 renal transplantations on patients with neurogenic bladder between 1992 and 2010.

It has been reported that among patients with intra-vesical pressure $>40 \mathrm{~cm} \mathrm{H}_{2} \mathrm{O}, 80 \%$ have hydronephrosis and $68 \%$ have VUR [8]. A decrease in intra-vesical pressure could improve secondary upper urinary tract dysfunction in $66 \%-80 \%$ of such patients [9]. Therefore, we performed pre-operative cystoplasties in the three patients with bladder dysfunction. These patients had intra-vesical pressure $>40 \mathrm{~cm} \mathrm{H}_{2} \mathrm{O}$ or had confirmed upper urinary tract dysfunction and/or incontinence despite regular CICs. Therefore, we considered that it was necessary to improve their bladder compliance for preventing post-transplantation upper UTIs and preserving renal graft function $[10,11]$. Moreover, patients with VUR of Grade 3 or higher, will be at high risk of UTIs while being treated with post-operative immunosuppressant therapy. Thus, we resected the kidney in order to prevent the renal graft from getting infected [12]. Furthermore, bladders of many transplant recipients become remarkably atrophic and exhibit a state of disuse atrophy because of long-term anuria. This makes accurate evaluation of bladder function before transplantation difficult. Hence, we examined the urination states before renal transplantation (incontinence, urinary infection, etc.) in order to evaluate upper urinary tract function. In this study, we evaluated the risk factors for renal grafts in patients with neurogenic bladder, and we expected that the high intra-vesical pressure and chronic pyelonephritis would act as risk factors for renal graft failure [10]. We hypothesized that renal graft failure would proceed as shown in Fig. 1. Hydronephrosis and VUR would cause an upper urinary tract infection, and a lower urinary tract infection would result from chronic residual urine. As a result, these conditions would result in pyelonephritis and renal graft failure. Therefore, we considered that hydronephrosis, VUR and chronic residual urine were risk factors for renal graft failure (patient numbers: 2, 4, 6, 8, 9, 10 and 11). The other patients were placed in the low-risk group and post-operative prognosis was compared between the two groups.

No patients in the low-risk group required re-introduction of dialysis, but one patient in the 


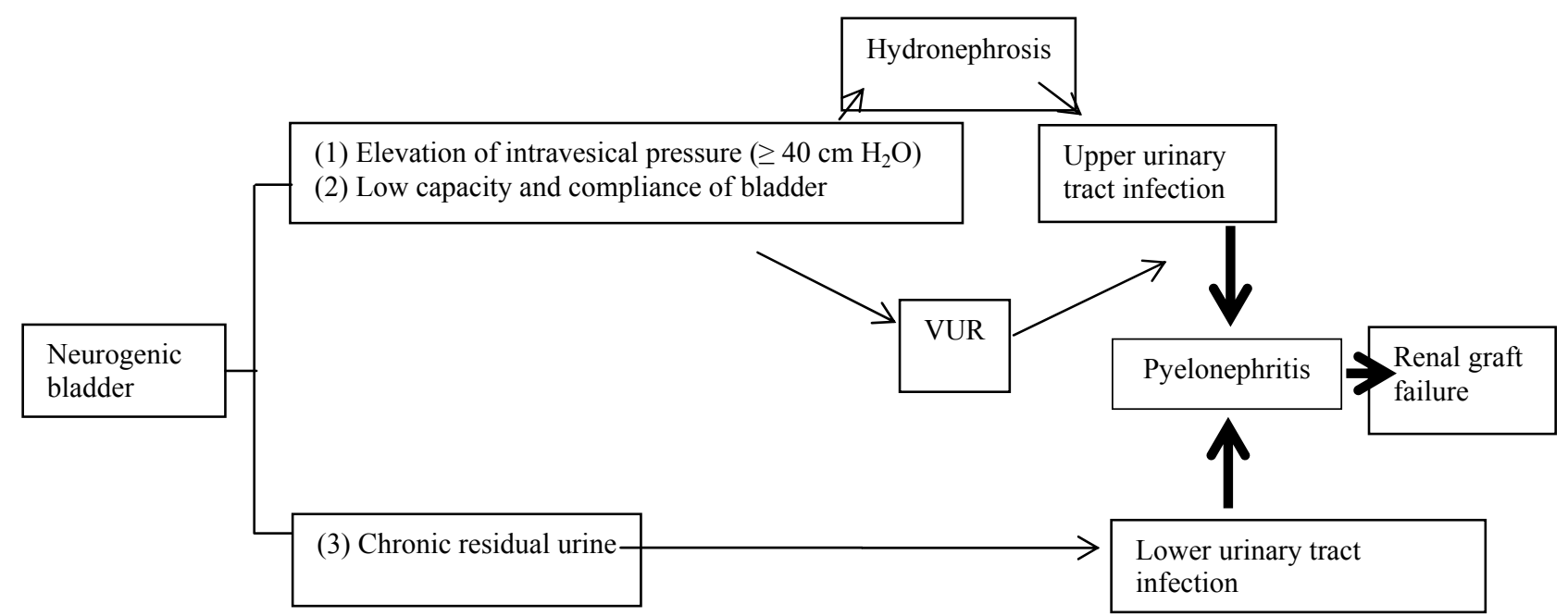

Fig. 1 The proceeding of renal graft failure among patients with neurogenic bladder.

Hydronephrosis and VUR would cause an upper urinary tract infection, and a lower urinary tract infection would result from chronic residual urine. These conditions would result in pyelonephritis, and frequent pyelonephritis causes disfunction of renal graft.

high-risk group who underwent pre-operative cystoplasty had graft failure and needed re-introduction of dialysis. We felt that it was necessary for the maintenance of the graft function to perform regular CIC. Therefore, the patient selection criterion for kidney recipients were as follows: the patients could take care of CIC or the indwelling catheter by themselves after the kidney transplant.

The recurrence of UTIs and renal stones, stenosis of the urinary tract, stoma hernias and stenosis of hernias have been reported as long-term complications after urinary diversions [12-15]. However, none of these complications were observed in our three patients who underwent pre-operative cystoplasties. The most important thing is that we treated all of our patients with CIC before the renal transplant. CIC was suggested by Guttman [16] in 1966 as a method of intermittent urination under full sterilization that cost time and effort. Subsequently, Lapides [17] reported that CIC was effective for improving urination states, and it became more popular as a method of intermittent urination. Many reports from the 1980s have shown that favourable mid/long-term prognoses of renal grafts can be expected with regular CIC [18-20].

These findings suggest that good prognosis can be expected after renal transplants if patients perform regular CIC, even if they do not have pre-operative risks for urinary tract complications. In addition, we performed surgical treatment such as cystoplasties and conservative treatment such as safe CICs in patients with the pre-operative complications including chronic residual urine, hydronephrosis and VUR, because these patients were pre-disposed to post-operative complications including upper UTIs and urinary dysfunction.

We believe that renal transplant recipients under immunosuppressant therapy can perform CIC and they should be encouraged to continue it for the preservation of the renal graft.

We had performed urinary diversions involving cystoplasties before or after renal transplantation in the patients with severe urinary tract disorder. That is, when a part of the urinary tract including the bladder was excised, irreversible blockage of the urinary tract was detectable, and the function of the urinary tract was disrupted. Thus, urinary-tract diversion or an ileal conduit was necessary for graft preservation.

Some reports have shown that patients treated with urinary diversions have a greater risk for UTIs, resulting in a possible increase in the frequency of chronic graft rejection [17, 21, 22]. Nevertheless, we performed transplantation even in patients with the 
severe neurological deformity if we could maintain infection of the urinary-tract origin under control and internal bladder pressure low, and our patients did not experience short-term complications of urinary diversions, but their long-term prognoses should be assessed carefully during follow-up. For example, all of our cases had suprapubic catheterization before the kidney transplant; replacement of the catheter is necessary for such cases every three weeks and confirmation that there were no signs of infection (e.g., flares) was necessary during the catheter use in the stated periods. In addition, the use of night balloon catheters is uncomfortable with regard to patient quality of life. This could be avoided by improvement of bladder compliance, which would prevent urinary tract complications without requiring the use of night balloon catheters. The indications for urinary diversion should be examined carefully in future with a careful evaluation of its advantages and disadvantages.

\section{Conclusion}

In patients with neurogenic bladder, the risks of renal graft failure are higher in those with chronic residual urine and elevated intra-vesical pressure. But we could preserve the function of the graft in the high-risk group, depending on the diagnosis before the kidney transplant by appropriate management after a kidney transplant in such cases. Determination of such a risk before a transplant was useful when we had to decide whether any surgical or conservative treatment was necessary. Such a risk was not related to which type of cystoplasty had to be performed.

In such high-risk patients, improvement of pre-operative and post-operative compliance should be attempted to prevent post-operative UTIs and protect renal graft function. For example, for the cases with high vesicoureteral reflux before the transplant, it was necessary to resect any residual kidney for prevention of infection because the residual kidneys could possibly cause pyelonephritis after transplant.

Furthermore, particular care should be taken in the post-operative management of these patients. In conclusion, our results suggest that regardless of risk, a favourable mid/long-term prognosis of renal grafts can be expected through appropriate pre-operative or post-operative management based on the pre-operative evaluations of the patient's urinary pathology.

\section{References}

[1] Kari, A. 2006. "Neuropathic Bladder as a Cause of Chronic Renal Failure in Children in Developing Countries."Pediatr. Nephrol. 21 (4): 517-20.

[2] Alfrey, E. J., Salvatierra, O. Jr., Tanney, D. C., Mak, R., Scandling, J. D., Dafoe, D. C., Hammer, G. B., Orlandi, P. D., Page, L., and Conley, S. B. 1997. "Bladder Augmentation Can Be Problematic with Renal Failure and Transplantation." Pediatr. Nephrol. 11 (6): 672-5.

[3] Nahas, W. C., Mazzucchi, E., Arap, M. A., Antonopoulos, I. M., Neto, E. D., Ianhez, L. E., and Arap, S. 2002. "Augmentation Cystoplasty in Renal Transplantation: A Good and Safe Option-Experience with 25 Cases." Urology 60 (5): 770-4.

[4] McInerney, P. D., Picramenos, D., Koffman, C. G., and Mundy, A. R. 1995. "Is Cystoplasty a Safe Alternative to Urinary Diversion in Patients Requiring Renal Transplantation?" Eur. Urol. 27 (2): 117-20.

[5] Cairns, H. S., Leaker, B., Woodhouse, C. R. J., Rudge, C. J., and Neild, G. H. 1991. "Renal Transplantation into Abnormal Lower Urinary Tract." Lancet 338 (8779): 1376-9.

[6] Basiri, A., Otoukesh, H., Simforoosh, N., Hosseini, R., and Farrokhi, F. 2007. "Kidney Transplantation in Children with Augmentation Cystoplasty." J. Urol. 178 (1): 274-7.

[7] Fontaine, E., Gagnadoux, M. F., Niaudet, P., Broyer, M, and Beurton, D. 1998. "Renal Transplantation in Children with Augmentation Cystoplasty: Long-Term Results." J. Urol. 159 (6): 2110-3.

[8] McGuire, E. J., Woodside, J. R., Borden, T. A., and Weiss, R. M. 1981. "Prognostic Value of Urodynamic Testing in Myelodysplastic Patients.” J. Urol. 126 (2): 205.

[9] Flood, H. D., Ritchey, M. L., Bloom, D. A., Huang, C., and McGuire, E. J. 1994. "Outcome of Reflux in Children with Myelodysplasia Managed by Bladder Pressure Monitoring.” J. Urol. 152 (5Pt1): 1574.

[10] DeFoor, W., Minevich, E., McEnery, P., Tackett, L., Reeves, D., and Sheldon, C. 2003. "Lower Urinary Tract Reconstruction Is Safe and Effective in Children with End Stage Renal Disease.” J. Urol. 170 (4): 1497-500. 
[11] Stein, R., Wiesner, C., Beetz, R., Schwarz, M., and Thüroff, J. W. 2005."Urinary Diversion in Children and Adolescents with Neurogenic Bladder: The Mainz Experience. Part I: Bladder Augmentation and Bladder Substitution-Therapeutic Algorisms." Pediatr. Transplant 20 (7): 920-5.

[12] Panaretto, K., Craig, J., Knight, J., Howman-Giles, R., Sureshkumar, P., and Roy, L. 1999. "Risk Factors for Recurrent Urinary Tract Infection in Preschool Children." J. Paediatr. Child Health 35 (5): 454-9.

[13] Rattazzi, L. C., Simmons, R. L., Markland, C., Casali, R., Kjellstrand, C. M., and Najarian, J. S. 1975. "Calculi Complicating Renal Transplantation into Ileal Conduits." Urology 5 (1): 29-31.

[14] Firlit, C. F., and Merkel, F. K. 1977. "The Application of Ileal Conduits in Pediatric Renal Transplantation." $J$. Urol. 118 (4): 647-50.

[15] Glass, N. R., Uehling, D., Sollinger, H., and Belzer, F. 1985. "Renal Transplantation Using Ileal Conduits in 5 Cases." J. Urol. 133 (4): 666-8.

[16] Guttmann, L., and Frankel, H. 1996. "The Value of Intermittent Catheterization in the Early Management of Traumatic Paraplegia and Tetraplegia." Paraplegia 4 (2):
63-94.

[17] Lapides, J., Diokon, A. C., Lowe, B. S., and Kalish, M. D. 1974. "Followup on Unsterile Intermittent Self-catheterization." J. Urol. 111 (2): 184-7.

[18] Flechner, S. M., Conley, S. B., Brewer, E. D., Benson, G. S., and Corriere, J. N. Jr. 1983. "Intermittent Clean Catheterization: An Alternative to Diversion in Continent Transplant Recipients with Lower Urinary Tract Dysfunction.” J. Urol. 130 (5): 878-81.

[19] Stanley, O. H., Chambers, T. L., and Pentlow, B. D. 1983. "Renal Transplantation in Children with Occult Neurogenic Bladder Drained by Intermittent Self-catheterization.” Brit. Med. J. 286 (6380): 1775.

[20] Shneidman, R. J., Pulliam, J. P., and Barry, J. M. 1984. "Clean Intermittent Self-catheterization in Renal Transplant Recipient." Transplant 38 (3): 312-4.

[21] Kass, E. J., Koff, S. A., Diokno, A. C., and Lapides, J. 1981. "The Significance of Bacilluria in Children on Long-Term Intermittent Catheterization.” J. Urol. 126 (2): 223-5.

[22] Middleton, A. W. Jr., Hendren, and W. H. 1976. "Ileal Conduits in Children at the Massachusetts General Hospital from 1955 to 1976." J. Urol. 115 (5): 591-5. 